\title{
ASBESTO CONTINUA MATANDO
}

Asbesto (ou amianto) é um mineral fibroso de silicato que tem sido utilizado mundialmente desde o final do século XIX por conta de sua propriedade de isolamento térmico. O termo "asbesto" refere-se a diversas formas comerciais que são classificados em dois grupos principais; 1 ) serpentina (com fibras encaracoladas), também conhecida como crisótilo ou "asbesto branco"; e 2) anfíbola (com fibras retas), que inclui o crocidolite (asbesto azul ou riebeckite), amosite (asbesto castanho ou cumingtonita-grunerita), asbesto tremolite, asbesto actinolite e asbesto antofilite. Asbesto crisótilo tem sido, e ainda é a forma mais extensivamente extraída e usada (acima de 90\% da produção mundial no passado, e atualmente 99\%) (Stayner et al., 2013).

A exposição ao asbesto pode causar 'asbestose', uma doença crônica de fibrose dos pulmões que num estágio mais avançado leva à falhas na respiração e lesões severas na pleura, incluindo efusão e placas. Além do mais todas as formas de asbestos são reconhecidas pelas propriedades cancerígenas, entretanto com potencias diferentes (crocidolite sendo considerado pior do que amosite e amosite sendo pior do que crisótile). A exposição ao asbesto está associada ao aumento no risco de mesotelioma e câncer no pulmão, laringe e ovário, enquanto que a evidência em relação a outros sítios (faringe, estômago, cólon e reto) é ainda considerada limitada (IARC, 2012). Há uma pandemia mundial de doenças relacionadas ao asbesto, com base nisto estima-se que aproximadamente 107.000 pessoas morrem anualmente de mesotelioma maligno (MM), câncer do pulmão, ou asbestose (Stayner et al, 2013).

Entre os cânceres relacionados ao asbesto, MM tem a peculiaridade de ser induzido apenas pelo asbesto (ou outra fibra de asbesto, como erionita e fluoro-edenite). MM pode afetar os quatro tecidos mesotelial: pleura (mais do que $90 \%$ dos casos), peritônio $(<10 \%)$ e muito raramente o pericárdio e a túnica vaginalis testis. Assim usaram-se extensamente a incidência e mortalidade do câncer MM e pleural para monitorar o impacto na saúde, da exposição ao asbesto mundialmente.

O maior peso da incidência e mortalidade do MM encontra-se em países que começaram a usar asbesto há muitas décadas (no Leste Europeu, América do Norte e Oceania). Embora muitos deles baniram a produção, importação e uso de asbesto (http://ibasecretariat.org/alpha_ban_list.php), o ápice da frequência de MM ainda não foi registrado por causa do longo período de latência (lapso temporal prolongado) entre exposição e ocorrência de MM. Em países recém industrializados que estão usando asbesto (e em alguns casos estão aumentando) - Ásia, Leste Europeu e América do Sul - a incidência do MM é relativamente baixa; entretanto, por várias razões, muitos pesquisadores e organizações científicas, incluindo a Organização Mundial de Saúde (OMS), a Comissão Internacional de Saúde do Trabalho (ICOH), a Organização Internacional do Trabalho e o The Joint Policy Committee of the Societies of Epidemiology, solicitaram uma proibição global na mineração, uso e exportação de asbesto (ICOH, 2014; Sim, 2013; Terracini, 2006). Entre os motivos estão: 1) Em muitos países industrializados, a estatística atual do MM estão seriamente afetadas pela falta de dados sobre a mortalidade e incidência, falta de registros e codificação errônea (Delgermaa et al., 2011; Park et al., 2011); 2) Por conta do longo período de latência, pode-se antecipar que a ocorrência de MM aumente nas décadas que estão por vir, em paralelo ao uso de asbesto; 3) A exposição ao asbesto não afeta somente os trabalhadores, mas também as suas famílias e as pessoas que moram perto destas fabricas de asbesto, ou que estão expostos aos produtos contendo asbesto deteriorado, notavelmente os telhados feitos de fibras de amianto (Sim, 2013; Mensi et al., 2015); e 4) Embora seja difícil de avaliar, o asbesto tem maior impacto na ocorrência de câncer do pulmão do que na frequência de MM (McCormack et al., 2012).

Atualmente a incidência de MM no Brasil é baixa comparada a outros países como Itália que tem usado asbesto extensivamente por um longo período (IARC, 2014). Entretanto, as estatísticas de MM no Brasil são afetadas pela codificação incorreta das mortes e casos de MM (IARC, 2014). De qualquer modo, espera-se o aumento da incidência e mortalidade por MM nos anos que estão por vir no Brasil (Algranti et al., 2015). Até o momento, somente alguns estudos avaliaram o impacto do asbesto na saúde dos Brasileiros. Há necessidade urgente de mais trabalho nesta área. Por este motivo, a Universidade Federal do Paraná com o Departamento de

*Epidemiology Unit, Department of Preventive Medicine, Fondazione IRCCS Ca' Granda - Ospedale Maggiore Policlinico, Milan, Italy.

E-mail: carolina.mensi@unimi.it; dario.consonni@unimi.it 
Enfermagem, lançou um projeto sobre asbesto e MM colaborando com a Secretaria de Saúde de Curitiba e com a Fondazione IRCCS Ca' Granda Ospedale Maggiore Policlinico, um dos mais importantes hospitais de Milão, Itália. No período de 2015-2017, dois Epidemiologistas Italianos (MC e DC), que trabalham no Registro de Mesotelioma, na Lombardia, a maior (10 milhões de habitantes) e mais industrializada Região da Itália, irão colaborar com pesquisadores e profissionais de saúde de Curitiba num projeto patrocinado pela Fundação CAPES (Coordenação de Aperfeiçoamento de Pessoal com Nível Superior) em Brasília. Esperamos que este trabalho ajude a aumentar a conscientização dos efeitos do asbesto na saúde no Brasil; onde a percepção da magnitude dos efeitos (na saúde) que podem ser atribuídos ao asbesto ainda é baixa. 